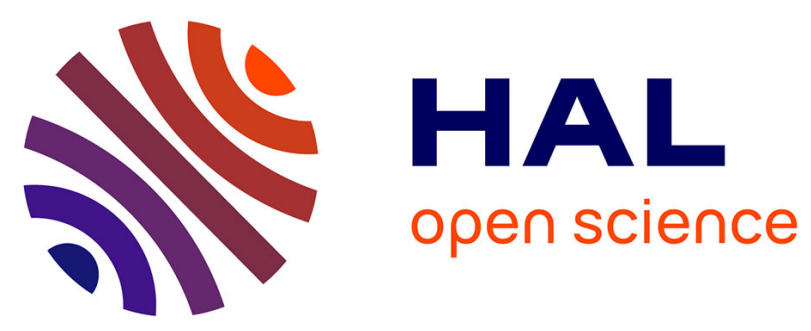

\title{
Are differences between social classes reduced by non-symbolic numerical tasks? Evidence from the ELFE cohort
}

\author{
Jean-Paul Fischer, Xavier Thierry
}

\section{- To cite this version:}

Jean-Paul Fischer, Xavier Thierry. Are differences between social classes reduced by non-symbolic numerical tasks? Evidence from the ELFE cohort. British Journal of Educational Psychology, 2021, 91, pp.286-299. 10.1111/BJEP.12363 . hal-02950526

\section{HAL Id: hal-02950526 \\ https://hal.univ-lorraine.fr/hal-02950526}

Submitted on 28 Sep 2020

HAL is a multi-disciplinary open access archive for the deposit and dissemination of scientific research documents, whether they are published or not. The documents may come from teaching and research institutions in France or abroad, or from public or private research centers.
L'archive ouverte pluridisciplinaire HAL, est destinée au dépôt et à la diffusion de documents scientifiques de niveau recherche, publiés ou non, émanant des établissements d'enseignement et de recherche français ou étrangers, des laboratoires publics ou privés. 
The final version of this paper was published as:

Fischer J.-P. \& Thierry X., (on line, July 2020; paper version not available on September 28, 2020). Are differences between social classes reduced by non-symbolic numerical tasks? Evidence from the ELFE cohort. British Journal of Educational Psychology. DOI: 10.1111/BJEP.12363

\section{Are differences between social classes reduced by non-symbolic numerical tasks?}

\section{Evidence from the ELFE cohort}

Background. Young children's mathematics abilities may be divided between symbolic and non-symbolic skills. Lower performance of SES disadvantaged versus advantaged children has already been established in symbolic math.

Aim. This study aimed to verify the effect of children's SES category on non-symbolic mathematical (numerical) performance.

Sample. The main sample comprises 4,955 children from the French longitudinal study, ELFE, tested when they were in the nursery school (4- to 5-year-olds).

Method. The distinction between symbolic and non-symbolic math skills based on the specific math assessment items used in the present study was verified on a larger sample. The SES-related difference in non-symbolic math skills was then examined in the ELFE sample only.

Results. The children's performance in non-symbolic maths is significantly and almost as strongly correlated with their family's income and their mother's level of education as their performances in symbolic maths. Linear regression mixed-effects modelling shows that the score in non-symbolic maths (out of 100) of children from families with below median income is 3.8 points lower than that of their peers from families with above median income.

Conclusion. Children from disadvantaged SES backgrounds perform significantly lower than those from advantaged backgrounds in non-symbolic maths. Even if non-symbolic math skills retain an educational interest, they should not reduce the importance of symbolic math skills in young children. 


\section{Introduction}

\subsection{The general importance of a symbolic/non-symbolic distinction in maths learning}

Distinguishing symbolic from non-symbolic representations of number is important, because "the early ability to perform arithmetical manipulations on nonsymbolic quantities uniquely predicts the later ability to perform complex manipulations (calculations) on symbolic quantities" (Barnes \& Raghubar, 2017, p. 89). Thus several researchers have speculated that individual differences in the acuity of non-symbolic number representations provide the basis for individual differences in symbolic mathematical competence (cf. Inglis, Attridge, Batchelor, \& Gilmore, 2011). This has been empirically supported at the behavioural level. Desoete, Ceulemans, De Weerdt, and Pieters (2012) showed that non-symbolic skills in kindergarten (ages 5-6) were predictively related to arithmetical achievement 1 year later and fact retrieval 2 years later (ages 7-8). Gilmore, McCarthy, and Spelke (2010) found that performance of non-symbolic arithmetic in kindergarten $\left(M_{\mathrm{age}}=5.8\right.$ years, Expt 1$)$ predicted children's mathematics achievement at the end of the school year (2 months later), independent of achievement in reading or general intelligence. This suggests that nonsymbolic abilities play a fundamental role in being associated with learning of the symbolic number system, thus laying the foundation for all further development in mathematics.

At the neuronal level, Piazza, Pinel, Le Bihan, and Dehaene (2007) confirmed that symbolic and non-symbolic representations of number share a common neural substrate. However, in complement to this common neural substrate, Eger et al. (2009) observed that activation patterns differ in the parietal regions of adult brains, depending on whether the activation patterns are evoked by formats of symbolic numbers (Arabic numerals) or nonsymbolic numbers (patterns of dots). 


\subsection{A social importance of a symbolic/non-symbolic distinction in maths}

The distinction between non-symbolic and symbolic representation of the number in preschool is particularly important with regard to egalitarian education. It is likely that children from disadvantaged backgrounds are less exposed to symbolic numbers in their family environment than their peers from non-disadvantaged backgrounds. The mathematics achievement gap between wealthy and poor children could then stem from this lesser exposure to conventional symbol systems. Despite the general importance of considering the sociocultural context in the implementation of mathematics learning environments (Verschaffel, Luwel, Torbeyns, \& Van Dooren, 2009), "there is no a priori reason to believe that low-SES [socio-economic status] children would have poor nonsymbolic number sense at entry to kindergarten" (Wilson, Dehaene, Dubois, \& Fayol, 2009, p. 231). A plausible assumption would be that the lower performance in mathematics of children from disadvantaged backgrounds results from their lack of experience in symbolic maths, while their performance in non-symbolic maths is equivalent to that of children from non-disadvantaged backgrounds.

\subsection{The direct tests of the non-symbolic maths performance as a function of SES}

The assumption that performance in non-symbolic maths by children from disadvantaged backgrounds is equivalent to that of children from non-disadvantaged backgrounds was tested both in the United States and in France. In the United States, it has been supported by substantial research by Jordan, Huttenlocher, and Levine $(1992,1994)$ and, to a lesser degree, by Gilmore et al. (2010).

Jordan et al. (1992, 1994) categorized pupils as disadvantaged (or low-income) if their families qualified for free- or reduced-price school lunch programmes, indicating that they 
were at the poverty level. The middle-income group originated in families that were not characterized by economic difficulty. Jordan et al. devised a non-verbal calculation requiring the child to find the correct solution to an arithmetical problem, an exact numerical array resulting from another through additive or subtractive transformation, the child having observed only the initial array and the applied transformation. This task may follow a nontransformation, thus reducing it to an exact numerical reproduction of what the child has just seen but which is hidden when the child is asked to reproduce it. Consequently, Jordan et al. (1992) found that the two income groups did not differ in performance on the nonverbal calculation task. Huttenlocher, Jordan, and Levine (1994) further demonstrated that a mental model of collection and (where applicable) transformation "in which imagined entities and transformations are mapped onto actual objects and movement" (p. 285) sufficed to resolve the task.

Gilmore, McCarthy, and Spelke (2010) did not use the non-verbal exact calculation designed by Jordan et al. (1992, 1994), but an approximate non-verbal calculation task. In their Experiment 2 children were classified either as low-SES ( $n=16 ; M_{\text {age }}=6.0$ years) or middle-SES ( $n=46 ; M_{\text {age }}=5.9$ years) based on their qualification for free and reduced lunch, respectively. Furthermore, in a comparison study of non-symbolic addition, Gilmore et al. drew the children ( $n=21 ; M_{\text {age }}=5.8$ years) from a higher socioeconomic community. In the latter comparison, Gilmore et al. found that children in the more advantaged community did not perform significantly better than their less advantaged peers on the test of non-symbolic addition. This result replicates, with an approximate calculation task, the absence of difference between the disadvantaged and non-disadvantaged children found by Jordan et al. $(1992,1994)$. 
In France, Fischer and Bocéréan (2004) tested 400 children, 3 to 5 and a half years old ( 80 children in each 6 -months age group), with a non-verbal test analogous to that used by Jordan et al. $(1992,1994)$ and Huttenlocher et al. (1994). The children were classified into three groups according to their parent's occupation: advantaged, average, or disadvantaged. Fischer and Bocéréan found a significant group effect, with the advantaged group performing much higher than the average group, and the latter performing higher than the disadvantaged group. The authors reported no effect size and no focused contrast, however.

\subsection{Some indirect tests of the non-symbolic maths performance as a function of SES}

With the exception of Fischer and Bocéréan (2004), only Jordan, Kaplan, Nabors-Oláh, and Locuniak (2006) have used Jordan et al.'s $(1992,1994)$ non-verbal exact calculation task, to our knowledge. In this general, longitudinal study, the mean age at entry into kindergarten was 5.58 years. The participants' status in free or reduced-price lunch programmes determined their low-income or middle-income classification. The research tested the assumption of more equal performance in non-verbal and verbal calculation between socially disadvantaged children and other children. This research established that the rate of development of non-verbal calculation, beginning at the end of nursery school and in the first 2 years of primary school, was the same for children from middle-income families and lower-income families. It thus appears to confirm the hypothesis of greater equality in nonverbal calculation, the authors writing that their "findings corroborate those of Huttenlocher and colleagues, which revealed that nonverbal calculation abilities are less sensitive to social class than are conventional story problems" (p. 170). Furthermore, in their article on learning difficulties in mathematics, Jordan and Levine (2009) also noted that "nonverbal calculation ability varies less across social classes than does the ability to solve verbal calculations (which clearly favors middle- over low-income children)" (p. 62). 


\subsection{The importance of verifying equality between children in non-symbolic maths}

In France, educational inequalities are particularly acute. The correlation between socioeconomic background and performance is much more emphatic than in most of the other OECD countries. In the Programme for International Student Assessment (PISA), an increase of one unit in the economic, social, and cultural status indicator leads to an average 39-point increase in the mathematics score in the OECD countries. The increase in France is 57 points, the sharpest of any OECD country (Keskpaik \& Salles, 2013). However, the encouraging results of Jordan et al. (1992, 1994) and Gilmore et al. (2010) were not reproduced in France by Fischer and Bocéréan (2004).

The discordance between the findings of Fischer and Bocéréan (2004) and both those of Jordan et al. $(1992,1994)$ and Gilmore et al. (2010) makes a new approach to the issue of greater equality among children in non-symbolic maths that much more desirable, given that he non-influence of social stratum on non-symbolic maths performance has a great educational and sociological interest. We re-examined the question with a sample of children participating in the French Longitudinal Study of Children (Enquête longitudinale française depuis l'enfance [ELFE]) (see Charles et al., 2020). The children were tested in nursery school at ages 4-5 on both verbal, symbolic numerical knowledge, and on nonverbal, non-symbolic activities in which they had to respect the number. This reexamination - the major objective of this article-was made possible by the comprehensive knowledge of the family environment of the children in the ELFE study. Given the discordance between the results obtained in the United States and France, our study avoids formulating directional hypotheses and must therefore be considered exploratory. 


\section{Method}

\subsection{Participants}

Over 18,000 newborns were recruited across metropolitan France in 2011 as part of the ELFE study. The recruitment method is fully described in Charles et al. (2020). Five years after recruitment, most children were attending the second year of nursery school in their place of residence. Consequently, in general there was just one ELFE child per class. The experimental attrition inherent in any long-term longitudinal study was increased substantially through the strict anonymity of the children (whose teachers were unaware that they were part of the ELFE cohort before being informed) and teachers volunteering to administer and code the tests. This explains why there are just 4,955 ELFE children for whom we have complete data on the 24 items selected for numeracy. The children's mean age is 4.82 years old $(S D=0.19)$ and $49.6 \%$ of them are girls.

To avoid isolating the ELFE child, initially the only one concerned by the test, the ELFE research designers asked the child's teacher, where possible, to simultaneously test three other classmates closest in age to the ELFE child. For these 10,449 non-ELFE children, no information is available apart from their sex and age. Yet, when added to the ELFE children, these individuals serve to verify the test's psychometric properties. This verification is thus based on the observation of 15,404 children with age comparable to that of the ELFE children.

\subsection{Items}

\subsubsection{All items}




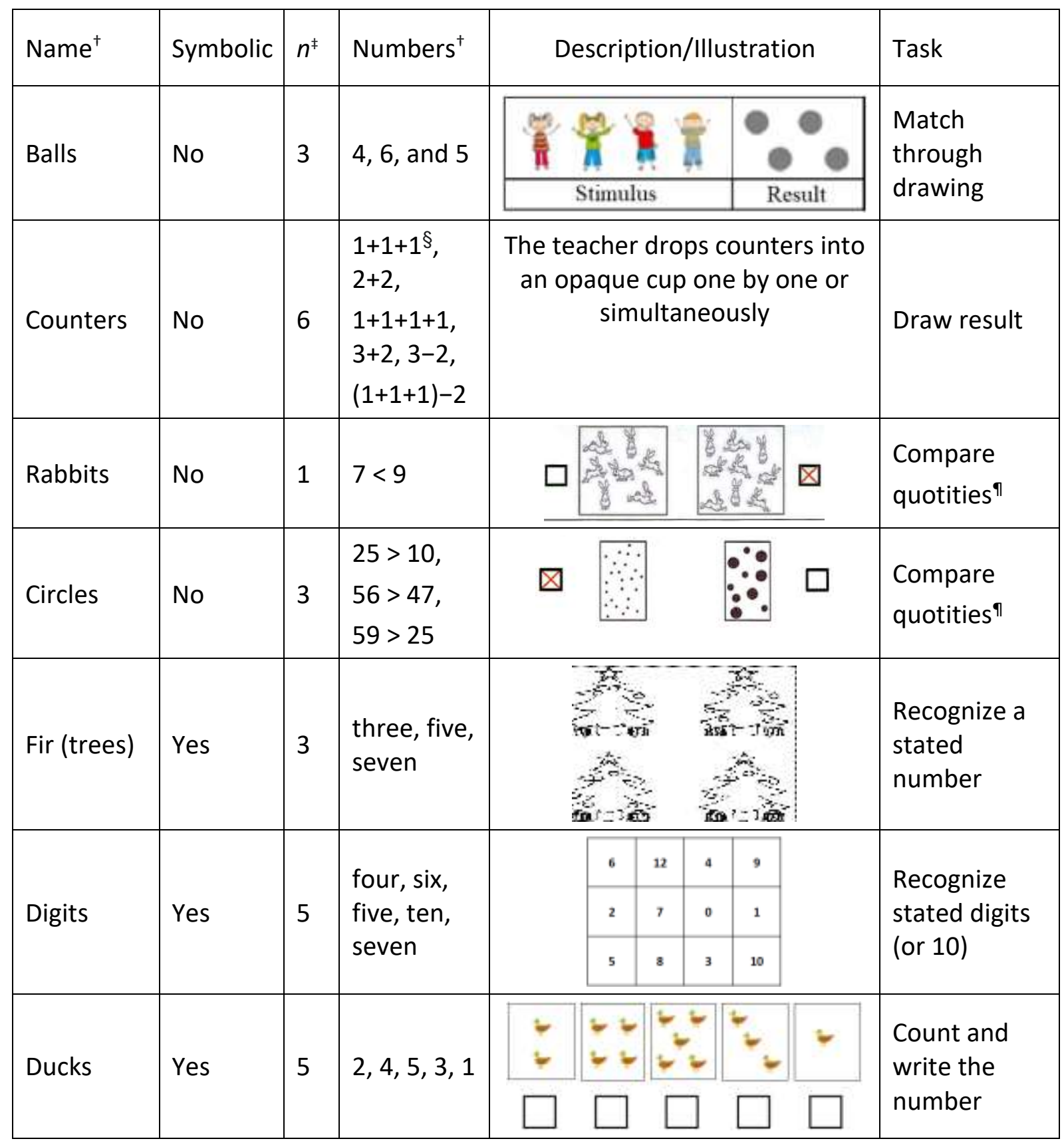

Figure 1. Description of the items used in the assessment.

† The trials and numbers concerned are reported in order of appearance in the test.

$¥$ Numbers of items

$\S$ The additive or subtractive notations indicate that the counters, or groups of counters, are added or removed one after the other.

П Quotity is the property of being or representing a particular number of discrete things (as distinct from an amount or size).

Almost all the items listed and described in Figure 1 are assessed with a 1 (success) or 0 (failure). However, the child may obtain the score of 0.5 in the "Ducks" subtest for counting the number correctly but incorrectly writing it (notably mirrored). 


\subsubsection{Non-symbolic items}

In the "Balls" subtest, the children were asked to draw balls (with simple circles, in any configuration) so that there was one (and only one) ball for each child.

The items in the "Counters" subtest were adapted from the non-verbal calculation task used in the research of Jordan et al. $(1992,1994)$ and Fischer and Bocéréan (2004), and applied to a group test. Children see that an opaque cup is empty. They see the first array of counters dropped into the cup, then the teacher adding or removing counters (transformation of the array), without ever seeing the added or remaining counters inside the cup. At the end, they draw the counters in the cup, in the form of simple circles in any configuration. After each item, the content of the cup is revealed.

In the comparison subtests ("Rabbits" and "Circles"), the children tick the collection containing the most items, rabbits or circles. Importantly, for the " $56>47$ " and " $59>25$ " item comparisons, the coloured circles (two or four colours) are presented in a rectangular frame, as in the "25>10" comparison shown in Figure 1, but the level of the least numerous circles is higher than that of the most numerous circles, either through artifice (visible fake floor) or greater circle size.

\subsubsection{Symbolic items}

In the "Fir" subtest, the children were asked to colour in one of four stars at the top of a fir tree, using a colour specified each time by the teacher; the number of fir tree balls, indicated orally by the teacher, served to determine which star to colour. For educational and aesthetic reasons, the children also coloured in the fourth tree-star, but only the first three coloured stars were taken into account in the assessments. 
In the "Digits" subtest, the children were asked to circle, in a $3 \times 4$ table with a colour specified each time by the teacher, the Arabic digit (or number for ten) indicated by the teacher.

In the "Ducks" subtest, the children had to count a collection of drawn ducks and write the number in numerical form.

\subsubsection{Selected items}

Two of the items led to correct answers differing very little from correct answers due to pure chance $(50 \%)$ and with a low correlation $(<.20)$ with all the other items. Likely, the Circles item " $56>47$ " led some otherwise well-performing children to answer based on the reached height, and this type of answer, based on a criterion other than number, perseverated for the following " $59>25$ " Circles item. These two items were excluded from the analysis, which thus concerns 24 items, of which 11 are non-symbolic, in that they do not require knowledge of the symbols (name and writing of the number), and 13 symbolic, in that they require an understanding of the number as verbalizations (Fir trees), their matching with written Arabic numerals (Digits), their use for counting, and their written production in Arabic digits (Ducks).

\subsection{Procedure}

In the last quarter of the school year, the teachers were provided with four booklets for pupils, a guide on conducting the tests, and a grid for coding the results. A pilot test was led a year earlier to collect the teacher's observations and to adjust the materials, instructions and assessments. The easiness of the first item of each task avoided a practice phase, and the group test makes a stopping rule unsuitable. The children's results were corrected by the teachers, who then sent them on to the ELFE coordination unit. 
In general, the ELFE children were tested with three of their fellow pupils as suggested by the ELFE team. This was the case for $61.4 \%$ of the 4,955 ELFE children in our study sample, with $10.5 \%, 5.6 \%$ and $22.5 \%$, respectively, being tested with two, one, or no classmates. The teachers were informed that this assessment did not count as a screening or diagnostic test.

In addition to a booklet, the children were equipped with a pencil, an eraser and five colour crayons (blue, red, green, yellow, and orange). The teacher instructed the children not to answer aloud and not to copy each other. The part of the test devoted to mathematical tasks lasted around 25 minutes during school time. Another part, administered at a different point in time, was devoted to a non-standardized literacy-test.

\subsection{Attribution of socio-economic level}

Variables serving to discern the socio-economic or socio-cultural level of the ELFE children's families were collected via a survey addressed to the parents a year earlier. We first selected the education level of the mother because socio-occupational category appears less relevant for school success than has been thought (Le Donné \& Rocher, 2010). However, we also selected the household's income because this measurement of socio-economic level is better suited to the income criterion used by Jordan et al. $(1992,1994)$.

The mother's education level was classified in four, relatively well ordered categories: 1 = primary school or no school; 2 = middle school; 3 = high school; 4 = higher education. The household's monthly income per consumption unit (CU, as defined by the OECD) was used to calculate Spearman's rank correlation $\left(r_{\mathrm{s}}\right)$ with the performance in symbolic and nonsymbolic maths. For the mixed-effects modelling, the sample was split in two according to whether family income was higher (advantaged pupils) or lower (disadvantaged pupils) than the median income of the sample. 


\section{Results}

\subsection{Homogeneity of the items}

Measured using the Cronbach alpha coefficient, the coherence of all the test items is satisfactory at $\alpha=.842$. The symbolic items result in a satisfactory $\alpha=.825$, while the nonsymbolic items score a merely acceptable $\alpha=.714$.

\subsection{PCA of the correlation matrix}

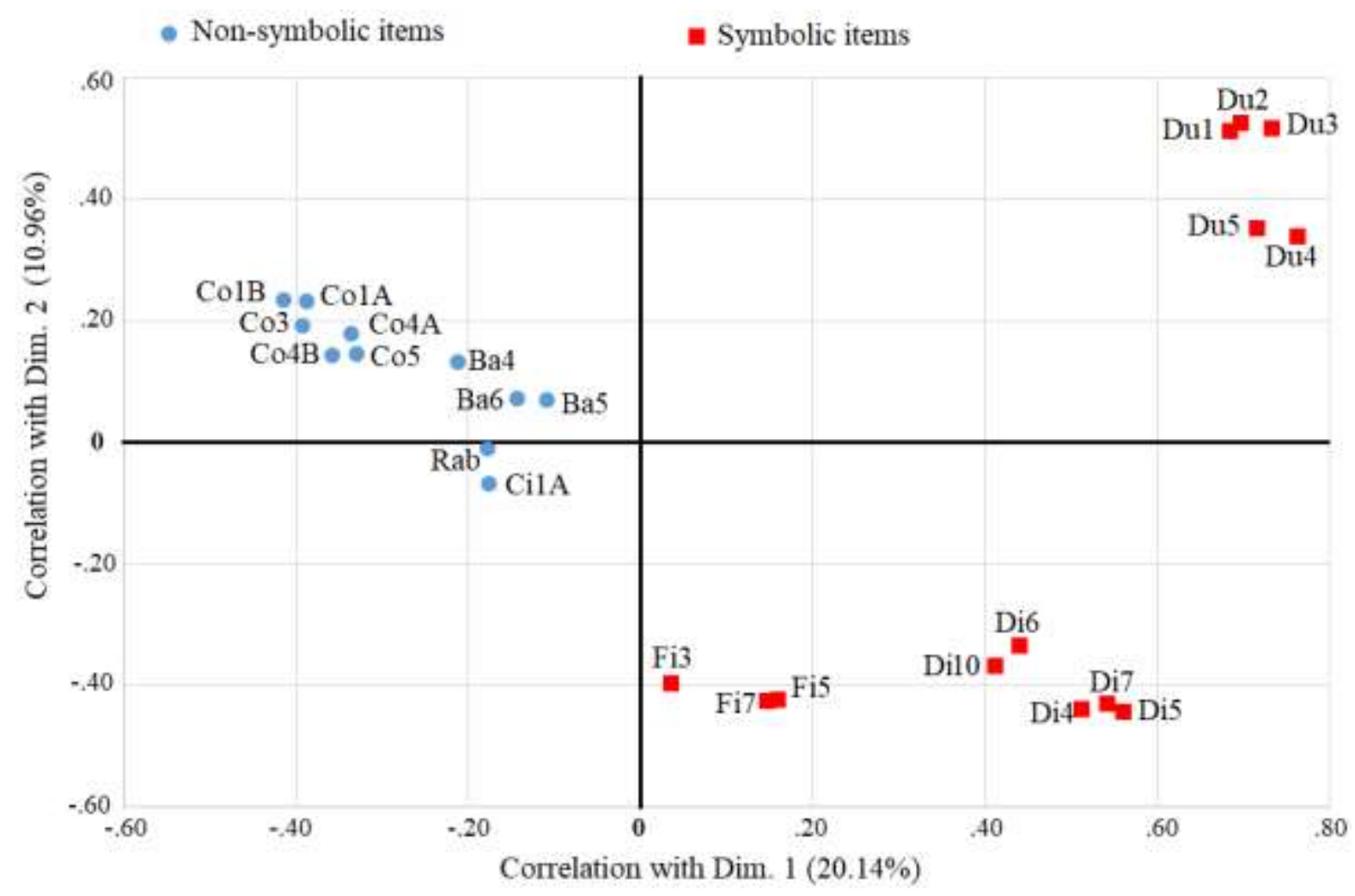

Figure 2. PCA of the matrix of inter-item correlations.

Notes. Co1A, Co1B, Co3, Co4A, Co4B, and Co5 designate the Counters items involving, respectively, the 3-2, (1 $+1+1)-2,1+1+1,2+2,1+1+1+1$, and $3+2$ calculations; $\mathrm{Ba} 4, \mathrm{Ba} 5$, and $\mathrm{Ba} 6$ designate the Balls items involving, respectively, 4, 5, and 6 children; Rab and Ci1A designate the comparisons of the Rabbits (7 vs. 9) and Circles (25 vs. 10) sets; Fi3, Fi5, and Fi7 designate the Fir items, with, respectively, 3, 5, and 7 fir tree balls; Di4, Di5, Di6, Di7, and Di10 designate the Digits items, involving, respectively, the recognition of the writing of 4, 5, 6, 7, and 10; Du1, Du2, Du3, Du4, and Du5 designate the Ducks items, with, respectively, 1, 2, 3, 4, and 5 ducks. 
In Figure 2, the items are represented by their correlations with the first two components of the principal component analysis (PCA) of the 15,404 participants' data. As the correlation between an item and a variable estimates the information they share (Abdi \& Williams, 2010), the information shared with the first component is substantial for the Ducks and Digits items, though less so for the others. But the key result of the PCA is the very clear distinction between symbolic and non-symbolic numerical knowledge. Axis 1 perfectly separates the non-symbolic and symbolic items, the former all being on the left (negative correlations) and the latter all on the right (positive correlations). At its two extremes, Axis 1 also opposes the non-symbolic Counters items (notably Co1B, which is significantly and negatively correlated with Component 1 ) and the symbolic Ducks and Digits items (all of them significantly and positively correlated with Component 1).

\subsection{Simple correlations}

Table 1 shows the correlations of symbolic and non-symbolic maths with the two social variables selected, as well as the difference of these correlations between the two categories of items tested with a comparison test for correlated correlation coefficients (Meng, Rosenthal, \& Rubin, 1992).

Table 1. Rank correlation differences of symbolic and non-symbolic maths with two measurements of the socio-economic or sociocultural level.

\begin{tabular}{lcccccc} 
Variable & $n$ & \multicolumn{2}{c}{$\begin{array}{c}\text { Correlation } r_{s} \text { with maths } \\
\text { symbolic }\end{array}$} & Don-symbolic & Difference & $p$ \\
\hline Household income $($ per CU) & & 4,846 & .093 & .109 & .015 & .323 \\
Education level (mother) & 4,942 & .095 & .101 & .006 & .687 \\
\hline † All correlations are significant at .001; ¥ Consumption Unit (scale OECD).
\end{tabular}


In addition, the correlations of the total (symbolic + non-symbolic) score of the numeracy test with the income per $\mathrm{CU}$ and mother's education level were compared with the same correlations of the literacy test. The two resulting coefficients were .106 and .116 for the numeracy test, and .141 , and .180 for the literacy test, all four significant at .001 . Regression analyses while controlling for literacy scores revealed that education level remains a significant predictor of numeracy scores, $t(4675)=2.938, p=.003$, but the significant effect of income disappears, $t(4582)=0.779, p=.436$.

\subsection{Mixed-effects regression model}

In the previous correlation analyses, the participants are taken as the sole random units of analysis. The results are then related to the items used and may not be generalized to other items. As stressed by Judd, Westfall, and Kenny (2017), such a generalization requires that the analysis addresses both the participants and items as random factors. To do so, individual observations need to be treated as units of analysis. This type of representation of individual observations can be achieved by transforming the file into one in which each participant is represented in 24 lines. Non-biased estimates of the effects of socio-economic class on the performance on non-symbolic items may then be arrived at by specifying a mixed-effects model.

We have included the analysis for non-symbolic items only, as these are the subject of our main concern. To obtain easy interpretable estimated parameters and to reduce the influence of some few high income values, the continuous Income variable was changed in a binary variable: +0.5 for a child whose parents' income is greater than the median income per UC in the whole sample, -0.5 for a child whose parents' income is lower (sometimes equal) than the median income per $\mathrm{CU}$ in the whole sample. Thus, participants are either advantaged (income: +0.5 ), or disadvantaged (income: -0.5 ), and each item is encountered in both conditions, favoured or non-favoured, albeit by different children. The result of the 
mixed effects linear regression analysis, with the Imer function from the Ime4 package (Bates, Maechler, Bolker, \& Walker, 2015) for R (R Core Team, 2015), are summarized in Table 2.

Regarding random effects, Table 2 shows that authorizing the random variation of the items was worthwhile, as their variance of correct response is about one third that of the participants. It also shows the mean difference between the two income groups hardly varies at all by items $\left(s^{2}=0.00027\right)$.

Table 2. Random and fixed effects in the mixed-effects linear regression of the influence of the dichotomized family income on the child's performance in the non-symbolic maths items.

\begin{tabular}{|c|c|c|c|c|c|c|c|c|}
\hline \multicolumn{3}{|c|}{ Random effects } & \multicolumn{6}{|c|}{ Fixed effect } \\
\hline Groups & Name & Variance & Name & Estimate & $S E$ & $d f$ & $t$ & $p$ \\
\hline \multirow[t]{2}{*}{ Items } & Intercept & 0.00948 & Intercept & 0.768 & 0.030 & 10.27 & 25.91 & $<.001$ \\
\hline & Slope & 0.00027 & Slope & 0.038 & 0.008 & 28.43 & 5.05 & $<.001$ \\
\hline Participants & Intercept & 0.02853 & & & & & & \\
\hline Residual & & 0.13113 & & & & & & \\
\hline
\end{tabular}

Regarding the fixed effect of income, it may be estimated that a child from a highincome family obtains a mean score (out of 1) 0.038 higher than that of a low-income child (otherwise comparable). The Student's $t$-test demonstrates that the effect of family income is highly significant. 


\section{Discussion}

\subsection{Key finding}

Simple correlation analyses confirm the well established results, namely that family income and mother's education level are significantly correlated with symbolic maths (see Table 1). But these analyses also show that the performance of young pupils in non-symbolic maths follows the same pattern, being significantly correlated with family income and the mother's education level.

A mixed-effects linear modelling, enabling random variation not just of the participants but of the items as well, was reported for the family-income per CU variable (dichotomized: advantaged vs. disadvantaged children) and for non-symbolic maths (see Table 2). The model clearly confirms that the performance in non-symbolic maths of young children from a disadvantaged socio-economic background is significantly lower than that of their peers from an advantaged background. It also estimates the difference at 3.8 points with scores out of 100 .

\subsection{A critical discussion of the empirical observations}

The results and theory of Jordan et al. $(1992,1994,2006)$ and Huttenlocher et al. (1994), as well as a result from Gilmore et al. (2010), may lead to the assumption that performance in non-symbolic maths is not correlated with a child's household income and, more indirectly, that correlations of performance in symbolic and non-symbolic maths with household income are different. Our key finding fails to validate the first assumption, given that we obtained an admittedly weak $\left(r_{S}=.109\right)$ but positive and significant $(p<.001)$ correlation between income and non-symbolic maths. We also confirmed, through a mixed-effects analysis controlling the random variance of the items, that family income has a significant 
influence on the performance of children in non-symbolic maths. Regarding the second assumption, we established that the difference in the correlations with family income between symbolic and non-symbolic maths is not significant $(p=.323)$. Despite the empirical demonstrations (Gilmore et al., 2010; Jordan et al., 1992, 1994, 2006) and an enlightening theorization (Huttenlocher et al., 1994), socially disadvantaged children do also appear disadvantaged in their performance of non-verbal and non-symbolic calculations. These empirical observations thus require a critical reassessment.

The initial research of Jordan et al. (1992) showed that middle-income children outperform lower-income children in all verbal tasks - story problems; the calculation of "How much is $n$ pennies and $m$ pennies?"; and number facts: "How much is $m$ and $n$ ?"-but not in all non-verbal tasks. Nevertheless, in graph form (Jordan et al., 1992, p. 648), the results show that middle-income children also perform better in non-verbal tasks, in both addition and subtraction. The non-significance of this observation may be due to the sample size, which, though respectable (42 children for each income level), is considerably smaller than that of the present study.

In a subsequent study, Jordan et al. (1994) compared the performance of young children on three types of response to non-verbal calculation tasks. First, the children had to construct an array of disks with the same number of disks as an array shown to them earlier and then hidden with a cover (non-verbal production). Second, they were asked to choose the correct number of disks from among four arrays, rather than constructing it (non-verbal recognition). Third, they had to name the number of hidden disks (verbal production). The first study, with 72 children aged 3, 4, and 5 from middle-income families, showed that the children's performance did not vary according to the type of answer. In contrast, the second study, with 48 children aged 3 and 4 from low-income families, showed that the children 
performed considerably better in the two non-verbal response formats than in the verbal format. The comparison between middle- and low-income children here is not direct, which is important because the difference between a significant result (in the second study) and a non-significant result (in the first) is not necessarily statistically significant.

The non-significance of the difference between symbolic and non-symbolic addition in Gilmore et al. (2010) can result from the study's lack of power, as in the research by Jordan et al. (1992). The result was obtained in comparing 62 not advantaged children to 21 advantaged children (the two subsamples are more completely described in Section 1.3). Therefore, with a bilateral t-test at the .05 level, the probability for detecting a small $(d=$ 0.20) difference was only .12 (approximately; see Cohen, 1988).

Consistent with our finding, Jordan et al. (2006) reported a secondary result demonstrating the influence of family income on non-verbal calculation. They studied the development of number sense among 411 pre-school children $\left(M_{\text {age }}=5.8\right.$ years $)$ from middle- and low-income families on four occasions, each time controlling for gender, age, and reading skills. At the end of nursery school, the performance of low-income children is substantially lower than that of their classmates in all tasks, including a non-verbal calculation task. This underperformance can be seen in Table 9 of Jordan et al. (p. 166, “Nonverbal calculation"). Forty-seven out of the 136 low-income children (34.6\%), compared with just 44 out of the 271 middle-income children (16.2\%), obtained low marks at the end of nursery school. Only $49+40=89$ low-income children out of $136(65.4 \%)$, compared with $99+128=227$ middle-income children out of $271(83.8 \%)$, obtained high marks at the end of nursery school. 


\subsection{A more theoretical contribution}

The stronger correlations with the SES variables in literacy than in numeracy suggest that the observed SES-related differences are not specific to maths, and may be due to more general SES-induced differences, notably through executive functions and language. As noted by Ellefson et al. (2020), there are numerous studies that have reported associations between executive functions and SES. Language also indubitably influences the symbolic maths performance (e.g., learning the verbal counting sequence: "One, two, three, ..."), but how can the family's language foster high performance in a non-verbal test?

Two examples suited to our test items can support an answer. Asking if the kitchen table is set correctly can lead to an one-to-one correspondence (e.g., "one plate for Mother, one for Father, ..."), as in our matching task. Asking if there are more apples than mandarins in a fruit basket with three large apples and four small mandarins can alert the child that more in number does not necessarily mean more in quantity, a distinction at the heart of the success in our second comparison item (see Figure 1).

More theoretically, non-symbolic number knowledge can provide a meaning to number symbols. Indeed, non-symbolic skills allow the development of mapping skills between number symbols and non-symbolic quotities. Counting plays an essential role in early developing such symbolic-non-symbolic mappings (Chan, 2020). This early development is important for later maths performance (Kolkman, Kroesbergen, \& Leseman, 2013).

These specifically cognitive explanations of the influence of the child's home environment on his or her non-symbolic maths performance do not exclude other, more general factors. Motivation has been proven to be a predictor of school performance, whose relative importance is at least comparable to intelligence irrespective of the considered 
subject matter (Steinmayr \& Spinath, 2009). Furthermore, student's motivation to learn was found significantly related to family SES (Liu \& Chiang, 2019), even in preschool (Józsa \& Caplovitz-Barrett, 2018), as SES disadvantaged children are less motivated than advantaged children. Because such general factors can indistinctly influence both non-symbolic and symbolic knowledge, they can also help explain why disadvantaged children perform lower in non-symbolic maths.

\subsection{Limits of the study}

The sample of 4,955 ELFE children cannot be considered representative of (French) children of this age (4-5) because the parents and teachers alike had to participate in the test on a voluntary basis. However, for the validation of the test itself, the additional recruitment of 10,449 children solely based on their age largely remedies this issue of representativeness. Moreover, our study is more focused on the items-symbolic, as opposed to non-symboliccomparison (a within-participant observation), than on the participants, lessening the impact of the non-representativeness of the participants.

This emphasis on the items may also serve to minimize another weakness of our study, namely that the test was assessed by the teachers of the pupils concerned. Teachers typically want their pupils to succeed at the end of the year, especially on items linked directly to their teaching (including the reading and writing of numbers). But that desire probably does not have a differentiated effect on children according to their social background and perhaps has less of an effect on non-symbolic items than on symbolic items. This tendency should therefore not bias the test of our main assumption on the influence (or non-influence) of social class on performance in non-symbolic maths. 
Last, though the number of participants in this study was considerable $(N=4,955$, and even 15,404$)$, the power of a study does not issue simply from the sample size (Judd et al., 2017). Increasing the number of items - thus striking a better balance between the number of participants and the number of items-would certainly strengthen the study. Nevertheless, most of the results consist of a rejection of a null hypothesis and are thus less concerned by the issue of the study's power of rejection.

\subsection{Conclusion}

The main finding - that children aged 4-5 from disadvantaged backgrounds show lower performances in non-symbolic maths than their more advantaged classmates-may seem discouraging from the standpoint of providing equal opportunities. But it does not discredit non-symbolic quantitative activities in preschool. Indeed, reporting on the pilot test, the teachers wrote that they particularly appreciated the non-symbolic Counters subtest, saying that it "addresses the fundamental concepts of numeration (three is one plus one plus one; and four is two plus two)" and that their students "loved the counters in the cup". However, the recent focus on non-symbolic numerical skills should not be detrimental for learning symbolic skills that "might be more important than non-symbolic skills in learning math" (Kolkman et al., 2013, p. 102).

\section{References}

Abdi, H., \& Williams, L. J. (2010). Principal component analysis. Computational Statistics, 2(4), 433-459. doi:10.1002/wics.101

Barnes, M. A., \& Raghubar, K. P. (2017). Neurodevelopmental disorders as model systems for understanding typical and atypical mathematical development. In D. C. Geary, D. Berch, R. Ochsendorf, \& K. Mann-Koepke (Eds.), Acquisition of complex arithmetic 
skills and higher-order mathematics concepts (pp. 67-97). London, UK: Academic Press. doi:10.1016/B978-0-12-805086-6.00004-7

Bates, D., Maechler, M., Bolker, B., \& Walker, S. (2015). Fitting linear mixed-effects models using Ime4. Journal of Statistical Software, 67(1), 1-48. doi:10.18637/jss.v067.i01.

Chan, W. W. L. (2020). Counting enhances kindergarteners' mappings of number words onto numerosities. Frontiers in Psychology, 11, 153. doi:10.3389/fpsyg.2020.00153

Charles, M. A., Thierry, X., Lanoë J. L., Bois, C., Dufourg, M. N., Popa, R., Cheminat, M., Zaros, C., \& Geay, B. (2020). Cohort profile: The French national cohort of children (ELFE): birth to 5 years. International Journal of Epidemiology, 49(2), 368-369j. doi:10.1093/ije/dyz227

Cohen, J. (1988). Statistical power analysis for the behavioral sciences ( $2^{\text {nd }}$ ed.). New York, NY: Taylor \& Francis.

Desoete, A., Ceulemans, A., De Weerdt, F., \& Pieters S. (2012). Can we predict mathematical learning disabilities from symbolic and non-symbolic comparison tasks in kindergarten? Findings from a longitudinal study. British Journal of Educational Psychology, 82(1), 64-81. doi:10.1348/2044-8279.002002

Eger, E., Michel, V., Thirion, B., Amadon, A., Dehaene, S., \& Kleinschmidt, A. (2009). Deciphering cortical number coding from human brain activity patterns. Current Biology, 19(19), 1608-1615. doi:10.1016/j.cub.2009.08.047

Ellefson, M. R., Zachariou, A., Ng, F. F. Y., Wang, Q., \& Hughes, C. (2020). Do executive functions mediate the link between socioeconomic status and numeracy skills? A cross-site comparison of Hong Kong and the United Kingdom. Journal of Experimental Child Psychology, 194, 104734. doi: 10.1016/j.jecp.2019.104734 
Fischer, J. P., \& Bocéréan, C. (2004). Les modèles du développement numérique à l'épreuve de l'observation [Numerical development models put to the proof of evidence]. Bulletin de Psychologie, 57(2), 191-202.

Gilmore, C. K., McCarthy, S. E., \& Spelke, E. S. (2010). Non-symbolic arithmetic abilities and mathematics achievement in the first year of formal schooling. Cognition, 115(3), 394-406. doi:10.1016/j.cognition.2010.02.002

Huttenlocher, J., Jordan, N. C., \& Levine, S. C. (1994). A mental model for early arithmetic. Journal of Experimental Psychology: General, 123(3), 284-296. doi:10.1037/00963445.123.3.284

Inglis, M., Attridge, N., Batchelor, S., \& Gilmore, C. (2011). Non-verbal number acuity correlates with symbolic mathematics achievement: but only in children. Psychonomic Bulletin \& Review, 18, 1222-1229. doi:10.3758/s13423-011-0154-1.

Jordan, N. C., Huttenlocher, J., \& Levine S. C. (1992). Differential calculation abilities in young children from middle- and low-income families. Developmental Psychology, 28(4), 644-653. doi:10.1037/0012-1649.28.4.644

Jordan, N. C., Huttenlocher, J., \& Levine, S. C. (1994). Assessing early arithmetic abilities: Effects of verbal and nonverbal response types on the calculation performance of middle- and low-income children. Learning and Individual Differences, 6(4), 413-432. doi:10.1016/1041-6080(94)90003-5

Jordan, N. C., Kaplan, D., Nabors-Oláh, L., \& Locuniak, M. N. (2006). Number sense growth in kindergarten: A longitudinal investigation of children at risk for mathematics difficulties. Child Development, 77(1), 153-175. doi:10.1111/j.14678624.2006.00862.x 
Jordan, N. C., \& Levine, S. C. (2009). Socioeconomic variation, number competence, and mathematics learning difficulties in young children. Developmental Disabilities Research Reviews, 15(1), 60-68.

Józsa, K., \& Caplovitz-Barrett, K. (2018). Affective and social mastery motivation in preschool as predictors of early school success: A longitudinal study. Early Childhood Research Quarterly, 45(4), 81-92. doi:10.1016/j.ecresq.2018.05.007

Judd, C. M., Westfall, J., \& Kenny, D. A. (2017). Experiments with more than one random factor: Designs, analytic models, and statistical power. Annual Review of Psychology, 68(1), 601-625. doi:10.1146/annurev-psych-122414-033702.

Keskpaik, S., \& Salles, F. (2013). PISA 2012 : baisse des performances des élèves de 15 ans en culture mathématique et augmentation des inégalités scolaires en France [Mathematical literacy in French 15-year-old students according to PISA 2012: decline in performance and increase in inequalities since 2003]. Paris: DEPP.

Kolkman, M., Kroesbergen, E., \& Leseman, P. (2013). Early numerical development and the role of non-symbolic and symbolic number skills. Learning and Instruction, 25, 95103. doi:10.1016/j.learninstruc.2012.12.001

Le Donné, N., \& Rocher, T. (2010). Une meilleure mesure du contexte socio-éducatif des élèves et des écoles [Better measurement of the socio-educational context in students and schools]. Éducation \& formations, 79, 103-115.

Liu, R., \& Chiang, Y. L. (2019). Who is more motivated to learn? The roles of family background and teacher-student interaction in motivating student learning. Journal of Chinese Sociology, 6(6). doi:10.1186/s40711-019-0095-z 
Meng, X. L., Rosenthal, R., \& Rubin, D. B. (1992). Comparing correlated correlation coefficients. Psychological Bulletin, 111(1), 172-175. doi:10.1037/00332909.111.1.172

Piazza, M., Pinel, P., Le Bihan, D., \& Dehaene, S. (2007). A magnitude code common to numerosities and number symbols in human intraparietal cortex. Neuron, 53(2), 293305.

R Core Team (2015). R: A language and environment for statistical computing. Vienna (Austria): R Foundation for Statistical Computing.

Steinmayr, R., \& Spinath, B. (2009). The importance of motivation as a predictor of school achievement. Learning and Individual Differences, 19(1), 80-90. doi:10.1016/j.lindif.2008.05.004

Verschaffel, L., Luwel, K., Torbeyns, J., \& Van Dooren, W. (2009). Conceptualizing, investigating, and enhancing adaptive expertise in elementary mathematics education. European Journal of Psychology of Education, 24(3), 335-359. doi:10.1007/BF03174765

Wilson, A. J., Dehaene, S., Dubois, O., \& Fayol, M. (2009). Effects of an adaptive game intervention on accessing number sense in low socio-economic status kindergarten children. Mind, Brain, and Education, 3(4), 224-234. doi:10.1111/j.1751228X.2009.01075.x.

Acknowledgements. The ELFE study was carried out jointly by INED, INSERM, EFS, SPF, INSEE, DGS, DGPR, DREES, DEPS, and CNAF, with the support of MESRI and INJEP. The study received state aidcoordinated by ANR in respect of the PIA with the reference of ANR-11EQPX-0038. 